\title{
Late outcomes after arterial switch operation for Taussig-Bing anomaly
}

\author{
Mathieu Vergnat, MD, ${ }^{a}$ Alban-Elouen Baruteau, MD,,${ }^{\mathrm{a}, \mathrm{b}}$ Lucile Houyel, MD, ${ }^{\mathrm{a}}$ Mohamedou Ly, MD, ${ }^{\mathrm{a}}$ \\ Régine Roussin, MD, ${ }^{\mathrm{a}}$ André Capderou, MD, PhD, ${ }^{\mathrm{b}, \mathrm{c}}$ Virginie Lambert, $\mathrm{MD}, \mathrm{PhD},{ }^{\mathrm{a}, \mathrm{c}}$ and Emre Belli, $\mathrm{MD}^{\mathrm{a}}$
}

Objective: To assess the long-term results of the arterial switch operation (ASO) for Taussig-Bing Anomaly (TBA) and identify risk factors affecting outcomes.

\begin{abstract}
Methods: Retrospective review and late follow-up was performed for all TBA patients from 1997 to 2010 (follow-up $>3$ years). Selection criteria included the absence of mitro-pulmonary continuity.

Results: Sixty-nine children underwent ASO at a median age of 24 days (interquartile range [IR] 11-125), with concomitant repair of aortic arch obstruction in $26(37.7 \%)$. Complex coronary anatomy $(\mathrm{n}=38 ; 55.0 \%)$ was common. Nine (13.0\%) patients had staged repair. Hospital mortality was 5.8\% (95\% confidence interval [CI], $1.6 \%-14.2 \% ; \mathrm{n}=4$ ). Median follow-up was 11.2 years (IR 7.2-13.8). Subsequent mortality was confined to the first postoperative year ( $\mathrm{n}=5,86 \%$ [95\% CI, 78\%-95\%]), 1-, and 10-year survival). Overall mortality was related to coronary pattern (Yacoub types $\mathrm{C}$ and $\mathrm{E}$ vs $\mathrm{A}$ and $\mathrm{D}$, multivariate, hazard ratio [HR] 12.2 [95\% CI, 1.2-122.1], $P=.03$ ). At latest follow-up, $96 \%$ of the survivors are asymptomatic, with normal ventricular function. Cumulative incidence of reintervention at 10 years was 53\% (95\% CI, 28\%-77\%). Concomitant aortic arch obstruction was a predictor of reintervention (multivariate, HR 2.9 [95\% CI, 1.1-7.4], $P=.03$ ). No mortality occurred upon reinterventions.

Conclusions: In the largest series to date of ASO for TBA, mortality is confined to the first postoperative year, and related to coronary artery pattern. Beyond the first year, needed reinterventions are frequent, but with sustained functional status and no mortality over $>10$ years follow-up. Aortic arch obstruction is the main predictor for reintervention. Despite a significant rate of early events, favorable long-term outcomes argue for use of the ASO in TBA patients. (J Thorac Cardiovasc Surg 2015;149:1124-32)
\end{abstract}

See related commentary on pages 1132-3.

The Taussig-Bing anomaly (TBA) is the third most common type of double outlet right ventricle. ${ }^{1}$ The definition includes bilateral subarterial coni with absence of pulmonary-mitral fibrous continuity. ${ }^{2,3}$ As a consequence of septal malalignment, with preferential flow from the left ventricle to the pulmonary artery (PA), a wide spectrum of malformations, including subaortic right ventricular outflow

From the Department of Pediatric and Congenital Heart Disease, ${ }^{a}$ Marie-Lannelongue Hospital-National Reference Center for Complex Cardiac Malformations-M3C, University of Paris-South, Le Plessis-Robinson; School of Medicine Paris-South, ${ }^{\text {b }}$ University Paris-South, Le Kremlin-Bicêtre; and INSERM U999, ${ }^{\text {c }}$ Marie-Lannelongue Hospital, Le Plessis Robinson, France.

Disclosures: Authors have nothing to disclose with regard to commercial support.

V.L. and E.B. contributed equally to this work.

Read at the 94th Annual Meeting of The American Association for Thoracic Surgery, Toronto, Ontario, Canada, April 26-30, 2014.

Received for publication April 21, 2014; revisions received Oct 10, 2014; accepted for publication Oct 18, 2014; available ahead of print Nov 21, 2014.

Address for reprints: Mathieu Vergnat, MD, Department of Paediatric and Congenital Heart Disease, Marie-Lannelongue Hospital, 133 ave de la Résistance, 92350 Le Plessis Robinson, France (E-mail: mvergnat@gmail.com).

0022-5223/\$36.00

Copyright (c) 2015 by The American Association for Thoracic Surgery

http://dx.doi.org/10.1016/j.jtcvs.2014.10.082 tract obstruction (RVOTO) and aortic arch obstruction, ${ }^{1}$ is frequently associated with this malformation. In addition, anatomic variations of the relationship of the great arteries and patterns of the coronary arteries have been described. ${ }^{4}$

Over decades, various management strategies have been applied to TBA, which has remained a surgical challenge. Many types of repair have been proposed. Anatomic repair, ${ }^{5,6}$ by intraventricular rerouting of the left ventricle to the aorta, with resection of the infundibular septum, can be achieved in selected cases. ${ }^{6-8}$ In addition, performing the arterial switch operation (ASO) and closure of the ventricular septal defect (VSD) has become the preferred management strategy, in many centers, with fairly consistent results. ${ }^{9-14}$ For more complex forms, Fontan circulation has been proposed. ${ }^{15}$ Compared with the ASO for D-transposition of the great arteries (TGA), the ASO for TBA has been associated with higher morbidity and mortality. This difference is attributed to the initial complexity of repair (morphologic features of TBA and associated lesions). Despite improved early results, the incidence of subneopulmonary obstruction and neoaortic regurgitation (AR) was notable, and reinterventions and reoperations were required. ${ }^{10-12}$

Given these debatable outcomes, controversy remains as to whether biventricular repair should be performed in these patients. Therefore, the aim of this study was to analyze the 


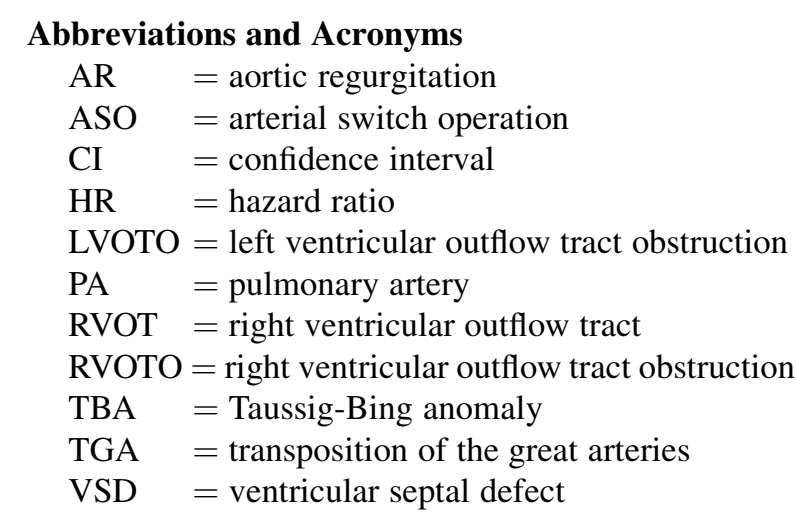

outcome after the ASO for TBA, in a large cohort. We sought to investigate risk factors associated with poor outcomes, which are useful to understand for decision making.

\section{MATERIALS AND METHODS \\ Inclusion Criteria}

We retrospectively reviewed the database for all patients with TBA admitted since 1997, with a follow-up of $>3$ years (up to 2010). After approval from the local institutional review board, with a waiver of consent, perioperative information was collected. From 1997 to 2010, a total of 72 consecutive children met our definition of TBA, and underwent the ASO at Marie-Lannelongue Hospital. Three patients (2 with multiple VSD [>2], 1 with unbalanced ventricles) were excluded.

\section{Anatomic Characteristics}

Using Van Praagh criteria, ${ }^{16}$ TBA was defined as: true double outlet right ventricle; great arteries originating predominantly from the right ventricle, following the $50 \%$ rule; bilateral coni; VSD beneath the PA, with no pulmonary stenosis; and no pulmonary-mitral continuity. The PA typically arises biventricularly, with the aorta positioned rightward and slightly anterior (D-transposition), or alongside the PA (side-by-side). ${ }^{1}$ Coronary anatomy was recorded based on Yacoub's classification. ${ }^{17}$

\section{Operative Data}

Procedures were performed under hypothermic cardiopulmonary bypass, with myocardial protection achieved by antegrade blood (38 of 69) or crystalloid (31 of 69) cardioplegia. The VSD was routinely exposed through the PA (58 of 69), or when possible, through atriotomy (5 of 69), or in difficult cases, through right infundibulotomy (6 of 69). Intraventricular rerouting of the VSD to the PA was performed with a polyester fabric patch. Both outflow tracts were carefully inspected, and resection of any obstructive infundibular structures was performed.

Aortic arch repair was performed under deep hypothermic circulatory arrest $\left(20^{\circ} \mathrm{C}\right)$, without $(10$ of 24$)$ or with $(14$ of 24$)$ selective cerebral perfusion through the innominate artery. The arch was augmented with a cryopreserved pulmonary homograft. A standard ASO (hinged trap-door incisions, Lecompte manoeuvre, regardless of the great vessels arrangement) was performed. The PA was reconstructed with autologous pericardium; in 4 patients, additional right-side shifting of the bifurcation was performed to prevent left PA stretching and right coronary anterior loop compression.

\section{Follow-up Data}

At last follow-up, patients were evaluated clinically and echocardiographically. Follow-up was completed in $89 \%$ of the early survivors. Median follow-up duration was 11.2 years (interquartile range: 7.2-13.8 years).

\section{Statistical Analysis}

Statistical analysis was performed using R version 3.1.1 statistical software (R-Foundation for Statistical Computing, www.r-project.org). Categoric variables are expressed as frequency (percentage); and continuous variables are expressed as mean ( \pm standard deviation) for values with normal distribution or median (interquartile range) for skewed data. Early death is defined as death in the hospital or within 30 days after surgery.

Survival was estimated by means of the Kaplan-Meier method with curves compared by the log-rank test. Cumulative incidence functions, obtained from the Nelson-Aalen estimator, were used to display the proportion of reintervention as time progressed.

Risk factors for time-related outcomes (mortality, reintervention) were tested using Cox regression analysis. Possible risk factors (with $\geq 8$ occurrences) included age, weight, staged strategy, previous banding, repair before age 30 days, aorta-PA relationship, native PA-aorta diameter ratio, arch obstruction, right or left outflow tract obstruction, coronary artery patterns, bypass and cross-clamp times, and RVOTO resection. Univariate analysis identified variables with $P \leq .2$ that were then entered in a stepwise fashion into a multivariable Cox proportional hazards regression model to determine the independent predictors of outcomes. The hazard ratio (HR) and $95 \%$ confidence interval $(\mathrm{CI})$ were reported for significant multivariable risk factors. $P$ values $<.05$ were considered statistically significant.

\section{RESULTS}

\section{Patient and Anatomic Characteristics}

The study cohort consisted of 69 patients. Patient preoperative characteristics are shown in Table 1. Nine (13\%) patients underwent staged repair with initial palliation: PA banding in 2, coarctation repair in 1, both procedures in 6 .

The cardiac anatomy of the patients is described in Table 1. Twenty-four patients ( $35 \%$ ) presented with a normal coronary artery pattern. The aortic arch was obstructed in 26 patients $(38 \%)$. The native PA was often dilated, and was more than twice the size of the aorta in 7 patients $(10 \%)$. The native PA-aorta diameter ratio was significantly higher in patients with arch obstruction $(1.7 \pm 0.3$ vs $1.5 \pm 0.3$, $P=.02$ ). Outflow obstruction was common (right, left, or both), found in 23 patients (33\%). Left ventricular outflow tract obstruction (LVOTO) was created by various mechanisms: posterior deviation of the upper rim of the interventricular septum $(n=4)$; mitral valve accessory tissue $(\mathrm{n}=3)$; conal septum $(\mathrm{n}=2)$; mitropulmonary muscular discontinuity $(\mathrm{n}=1)$; muscular bundle of Moulaert $(\mathrm{n}=1)$; and a combination of these $(\mathrm{n}=4)$.

\section{Operative Data}

The perioperative data are listed in Table 2. Of the 15 LVOTO dynamically identified on preoperative echocardiography, only 4 required LVOTO resections (of mitral accessory tissue, $\mathrm{n}=2$; of muscular bundle, $\mathrm{n}=2$ ).

\section{Mortality}

Hospital mortality occurred in 4 patients $(6 \% ; 95 \% \mathrm{CI}$, $1.6 \%-14.2 \%$ ), all after major events in the first postoperative day.

A child aged 33 days presented with side-by-side TBA (type E pattern), with coarctation, and severe 
TABLE 1. Demographic and anatomic characteristics $(n=69)$

\begin{tabular}{lc}
\hline \multicolumn{1}{c}{ Characteristic } & $\begin{array}{c}\mathbf{n}(\%) \text { or } \\
\text { median (IR) }\end{array}$ \\
\hline Demographic and preoperative & \\
Median age at surgery (d) & $24(11-125)$ \\
Median weight at surgery (kg) & $3.4(3.1-4.4)$ \\
Pulmonary hypertension & $8(12)$ \\
Left ventricular dysfunction & $2(3)$ \\
Aorta-pulmonary artery relationship & \\
Side by side & $47(68)$ \\
Aorta anterior and rightward & $22(32)$ \\
Native pulmonary artery-aorta diameter ratio & $1.5(1.4-1.7)$ \\
Ratio $\geq 2$ & $7(10)$ \\
Coronary artery pattern & \\
A & $24(35)$ \\
B & $0(0)$ \\
C & $3(4)$ \\
D & $7(10)$ \\
E & $35(51)$ \\
Commissural malalignment & $6(9)$ \\
Aortic arch obstruction & \\
Hypoplastic arch & $16(23)$ \\
Isolated coarctation & $10(14)$ \\
Outflow tract obstruction & \\
Subaortic RVOTO & $10(14)$ \\
Subpulmonary LVOTO & $15(22)$ \\
Other associated anomalies & \\
Straddling atrioventricular valve (mitral/tricuspid) & $18(26)[14 / 4]$ \\
Single additional VSD & $4(6)$ \\
Dysplastic native pulmonary valve \\
Bicuspid native aortic valve \\
Mitral abnormality* \\
\hline IR, Interquartile range; $R$ VOTO, right ventricular outflow tract obstruction; LVOTO, \\
grade-2 regurgitation, 1 parachute mitral valve. \\
\end{tabular}

biventricular outflow obstruction. A few hours after the repair, she developed right ventricular failure and subsequently died of intractable low-output syndrome. A child aged 14 days, with heart failure, was diagnosed with side-by-side TBA (type E pattern) with coarctation. Immediately after repair, right coronary stretching required repositioning, but the child subsequently died of intractable ventricular fibrillation. A child aged 24 days, with antero-posterior TBA (type $\mathrm{C}$ pattern with an intramural left coronary artery), underwent uneventful repair. At day 1, left coronary obstruction occurred, and he died suddenly of intractable ventricular fibrillation. A child aged 15 days, with side-by-side TBA (type E pattern), underwent uneventful repair but developed biventricular failure. At day 2, the stenotic right ventricular outflow tract (RVOT) was replaced with a xenograft conduit, with subsequent circulatory support. A coronary angiogram revealed an occluded circumflex artery, and the child subsequently died of intractable capillary leak syndrome.
TABLE 2. Operative and early postoperative data $(n=69)$

\begin{tabular}{|c|c|}
\hline Characteristic & $\begin{array}{l}\text { n }(\%), \text { mean }( \pm \mathrm{SD}), \\
\text { or median }(\mathrm{IR})\end{array}$ \\
\hline \multicolumn{2}{|l|}{ Operative times } \\
\hline Bypass, min & $184 \pm 64$ \\
\hline Cross-clamp, min & $114 \pm 33$ \\
\hline Circulatory arrest & $26(38)$ \\
\hline Circulatory arrest time, $\min$ & $30 \pm 7$ \\
\hline \multicolumn{2}{|l|}{ VSD tunnel procedure } \\
\hline $\begin{array}{c}\text { Through native pulmonary valve, } \\
\text { infundibulotomy, right atrium }\end{array}$ & 57 (83), $7(10), 5(7)$ \\
\hline $\begin{array}{l}\text { Polyester fabric, heterologous } \\
\text { pericardium, PTFE }\end{array}$ & $56(83), 12(17), 1(2)$ \\
\hline VSD enlargement & $4(6)$ \\
\hline \multicolumn{2}{|l|}{ Concomitant procedures } \\
\hline Aortic arch repair [without patch augmentation] & $26(38)[5(7)]$ \\
\hline RVOT (subneopulmonary) resection & $9(13)$ \\
\hline Native pulmonary root reduction & $5(7)$ \\
\hline RVOT (subneopulmonary) patch augmentation & $3(4)$ \\
\hline LVOTO (subneoaortic) resection & $4(6)$ \\
\hline Pulmonary bifurcation translation & $4(6)$ \\
\hline VSD closure & $2(3)$ \\
\hline Pulmonary artery banding & $1(2)$ \\
\hline Hospital mortality & $4(6)$ \\
\hline \multicolumn{2}{|l|}{ Complications } \\
\hline Delayed chest closure & $41(59)$ \\
\hline Elevated discharge RVOT gradient* & $5(7)$ \\
\hline Heart block requiring permanent pacemaker & $1(2)$ \\
\hline Length of stay in intensive care unit (d) & $7(5-11)$ \\
\hline
\end{tabular}

Subsequent mortality was confined to the first postoperative year ( $\mathrm{n}=5,86 \% ; 95 \% \mathrm{CI}, 78 \%-95 \%)$ survival rate, at 1 and 10 years (Figure 1,A). Myocardial ischemia was the primary cause. Three patients (aged 11, 25, and 317 days at surgery, respectively), all with type E coronary pattern, had an uneventful early postoperative course; they died suddenly at 51, 70, and 317 days postoperation, respectively. Only one autopsy could be performed, which showed stretching of the right coronary artery. Two patients (aged 10 and 56 days, respectively, at surgery) suffered severe postoperative ventricular dysfunction; one died of intractable ventricular fibrillation during implantation of a permanent pacemaker at 30 days, and a second died of an ischemic stroke at 143 days.

Neither early nor late survivals were affected by either relationship or size ratio of the great vessels. Multivariate analysis showed that longer bypass surgery time was a risk factor for early and overall mortality $(1.3 \% ; 95 \% \mathrm{CI}$, $0.2 \%-2.5 \%$; increased HR for each additional minute, $P=.02)$. In addition, in multivariate analysis, overall mortality was higher in types $\mathrm{C}$ and $\mathrm{E}$ versus types $\mathrm{A}$ and D coronary patterns (HR 12.2; 95\% CI, 1.2-122.1, 


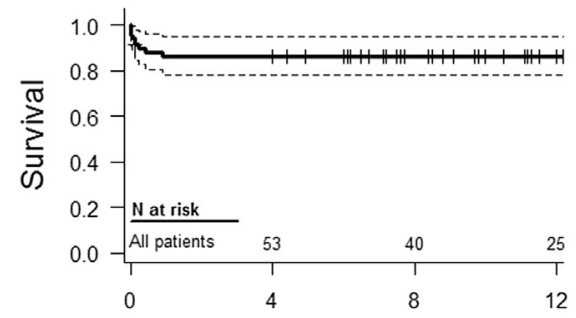

A Time after operation (years)

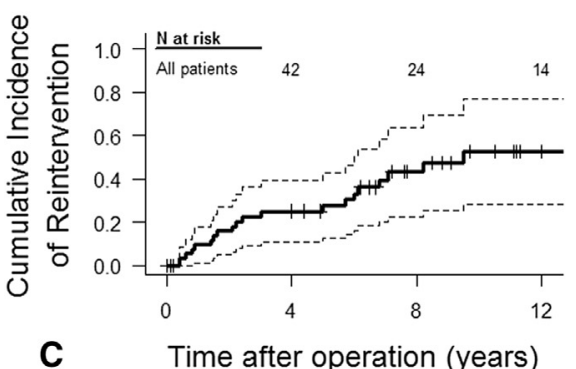

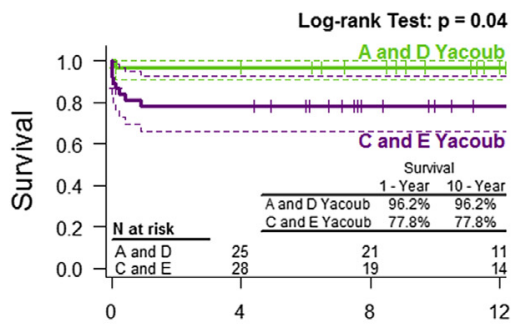

B Time after operation (years)

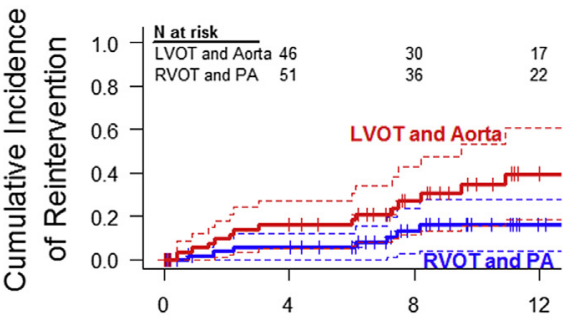

D

Time after operation (years)

FIGURE 1. A, Kaplan-Meier estimates for overall survival for all patients, and (B) by cluster of coronary pattern (Yacoub type A and D vs Yacoub type C and E). C, Nelson-Aalen estimates for cumulative incidence of surgical and catheter-based reintervention for all patients, and (D) for LVOT and aorta, and for RVOT and PA. LVOT, Left outflow tract; RVOT, right outflow tract; PA, pulmonary arteries.

$P=.03$ ) (Figure $1, B)$, and in the case of subpulmonary LVOTO (HR 4.3; 95\% CI, 1.1-17.7, $P=.04$ ).

\section{Reintervention}

Surgical or transcatheter reintervention was required in 21 hospital survivors, with a median time delay of 2.4 years (0.4-14.2 years) (Figure 1, C). The cumulative incidence rate of reintervention at 10 years was $53 \%(95 \% \mathrm{CI}$, $28 \%-77 \%$ ). No mortality occurred upon reinterventions. Twenty-seven procedures were performed on the left outflow tract and aorta; 21 were performed on the right outflow tract and PA (Table 3) (Figure 1, D).

TABLE 3. Surgical or transcatheter reintervention $(n=53)$

\begin{tabular}{lcc}
\hline \multicolumn{1}{c}{ Reintervention } & n (\%) & $\begin{array}{c}\text { No. of } \\
\text { procedures }\end{array}$ \\
\hline Any reintervention & $21(40)$ & 38 \\
Transcatheter reintervention & $9(17)$ & 13 \\
Aortic arch balloon angioplasty or stenting & & 8 \\
PA balloon angioplasty or stenting & & 5 \\
Surgical reintervention & $19(36)$ & 25 \\
Pulmonary arterioplasty & & 11 \\
Relief of LVOTO & & 8 \\
Aortic valve replacement & & 5 \\
Relief of RVOTO & & 5 \\
Septal defect closure & 4 \\
Recoarctation repair & & 3 \\
Aortic valve repair & & 3 \\
Coronary procedure & & 3 \\
\hline
\end{tabular}

PA, Pulmonary artery; LVOTO, left ventricular outflow tract obstruction; RVOTO, right ventricular outflow tract obstruction.
Regarding aortic outflow, subvalvar aortic obstruction was relieved by fibromuscular resection in 7 patients, patch septoplasty in 2, patch plication in 1, and Konno procedure in 1 . Aortic valve replacement was performed in 1 patient, 2 years postoperatively, for severe combined stenosis and $A R$, and in 4 patients at 6-8 years postoperatively, for severe AR. Regarding pulmonary outflow, 3 recurrent (among the 10 patients with RVOTO addressed at the initial ASO) and 6 new onset obstructions required 21 reinterventions. Surgical release of RVOTO was performed in 5 patients, by muscular band resection; in 2 of these, an additional heterotopic conduit was performed, because of a coronary anterior loop. Recoarctation $(\mathrm{n}=7)$ was managed by transcatheter procedures, and 3 of them required surgery with patch

TABLE 4. Possible factors associated with reintervention

\begin{tabular}{|c|c|c|}
\hline Factor* & $\begin{array}{c}P \text { value } \\
\text { (univariate) }\end{array}$ & $\begin{array}{c}\text { HR }(95 \% \text { CI }) ; P \text { value } \\
\text { (multivariate) }\end{array}$ \\
\hline \multicolumn{3}{|l|}{ Any reintervention } \\
\hline Aortic arch obstruction & .01 & $2.9(1.1-7.4) ; \quad P=.03$ \\
\hline Cross-clamp time & .02 & $1.01(0.99-1.03) ; P=.27$ \\
\hline \multicolumn{3}{|l|}{ Right-side reoperation } \\
\hline $\begin{array}{l}\text { Native PA-aorta diameter } \\
\quad \text { ratio } \geq 2\end{array}$ & .02 & $6.0(1.3-27.4)$ \\
\hline Preoperative subaortic RVOTO & .09 & $0.8(0.08-8.4) ; \quad P=.87$ \\
\hline \multicolumn{3}{|l|}{ Reoperation for AR } \\
\hline Aortic arch obstruction & .07 & $2.4(0.3-19.0) ; \quad P=.40$ \\
\hline Cross-clamp time & .06 & $0.99(0.97-1.03) ; P=.93$ \\
\hline
\end{tabular}


augmentation. Three coronary artery procedures included one ostial enlargement, a bypass graft at a subsequent procedure in the same patient, and one right ostium repositioning.

In univariate analysis (Table 4), aortic arch obstruction (HR 3.3; 95\% CI, 1.3-8.3, $P=.01$ ) and increased crossclamp $(1.7 \% ; 95 \% \mathrm{CI}, 0.2 \%-3.2 \%$, increased the HR for each additional minute, $P=.02$ ) were associated with further reintervention. In multivariate analysis, only aortic arch obstruction was a predictor of reintervention (HR $2.9 ; 95 \% \mathrm{CI}, 1.1-7.4, P=.03)$. When the pulmonary to aortic diameter ratio was $>2$, the right-side reoperation rate for RVOTO was higher (multivariate, HR 6.0; 95\% CI, 1.3-27.4, $P=.02$ ). Aortic arch obstruction was a risk factor for postoperative AR $\geq 2(P=.02)$.

\section{Late Outcomes}

At follow-up, all but 2 patients were in New York Heart Association functional class I. All but one paced patient maintained sinus rhythm. Normal biventricular function was present in all hospital survivors except one. This latter child already had severe preoperative dysfunction at the ASO, not tolerating a PA banding performed 5 months before.

Forty patients had normal echocardiographic assessment. Mild RVOTO (maximal gradient between 30 and $45 \mathrm{~mm}$ $\mathrm{Hg}$ ) was present in 4 , and 3 patients had mild LVOTO (maximal gradient between 30 and $50 \mathrm{~mm} \mathrm{Hg}$ ). Nine had grade- $2 \mathrm{AR}$, and 2 developed grade- $3 \mathrm{AR}$ (at 8 and 12 years after the procedure, despite having no cumulative risk factors for AR). Residual medically managed coarctation was present in 4 patients. One patient required heart transplantation for persistent ischemic heart failure, despite ostial coronary enlargement and bypass procedures, 7 years after the ASO.

\section{DISCUSSION}

Despite the substantial number of repair strategies proposed $^{7}$ since 1971, TBA still presents a surgical challenge. The complexity of this malformation is determined by specific morphologic features (intracardiac morphology, relationship of the great arteries, coronary anatomy) and by frequent associated lesions consecutive to native RVOTO (subaortic obstruction, aortic hypoplasia). These factors contribute to noteworthy complication, mortality, and reintervention rates. Today, the anatomic repair by a primary ASO in early infancy has been adopted as the method of choice. ${ }^{10-14}$ Applying this strategy for more than 2 decades, we have noted that mortality is confined to the first year after repair and is significantly related to the coronary artery pattern. Reinterventions are common, related to initial arch obstruction, but can be achieved with no mortality. Excellent late outcomes for such a complex malformation can be accomplished with this strategy.

\section{Mortality}

Mortality rates for ASOs in TBA vary, according to recent published literature, ${ }^{11,13,14}$ from $5.3 \%$ to $11 \%$. Low early mortality $(6 \%)$, and an $85 \%$ survival rate at 10 years, compare favorably with these series, and with the $13 \%$ mortality rate of TGA/VSD patients in a recent multiinstitutional report. ${ }^{18}$ In our experience, all deaths occurred in the first postoperative year. Similarly, among the 13 deaths reported in the recent literature, ${ }^{12-14} 11$ occurred in the first year. Beyond this point, survival was excellent, and efforts to improve operative results have to focus on the "early" postoperative period. The findings that mortality is coronary-related corroborate this early occurrence. Similarly, in our experience, ${ }^{19} 89 \%$ of coronary events after the ASO for TGA were observed within the first 3 months.

Risk for increased mortality was attributed to several factors, such as an unusual coronary pattern, ${ }^{12}$ staged repair, and consequently, higher operative weight. ${ }^{10}$ In our series, coronary pattern was a significant predictor of overall mortality. When comparing the risk to that associated with coronary transfer, the difference in the $21 \%$ mortality rate for the $\mathrm{C}$ and $\mathrm{E}$ patterns, versus $3 \%$ for the $\mathrm{A}$ and $\mathrm{D}$ patterns, in TBA patients of the present series, is similar to the $27 \%$ versus $5 \%$ rates reported in the literature for TGA. ${ }^{18}$ Thus, additional mortality from the ASO, when comparing TBA to TGA, is not related to the procedure applied to TBA patients, but to the higher rate of complex coronary anatomy in these patients. All 9 deaths were related to myocardial ischemia; 8 had complex coronary pattern.

In these complex patterns, more aggressive investigations (catheter-based or computed tomography) to identify lesions at risk for postoperative myocardial ischemia may help to reduce mortality after discharge. Our strategy includes systematic angiography before discharge for type $\mathrm{C}$ pattern and, for other types, only in patients with evidence (electric or echocardiographic) of myocardial ischemia. Lesions identified and associated with ischemia are to be treated first by balloon dilatation. For lesions not managed by percutaneous angioplasty, surgical revascularization should be performed, by ostial angioplasty or thoracic artery grafting. ${ }^{20}$

Increased bypass time was found to be associated with higher mortality rates, likely reflecting the complexity of the repair and coronary reimplantation. Rarely employed in our series, staged repair did not influence outcome. Associated anomalies, such as aortic arch obstruction $(38 \%)$ and side-by-side position of the great arteries $(68 \%)$, were frequent and did not influence mortality rates.

\section{Reinterventions}

Reintervention rates of $25 \%$ to $40 \%$ (surgical or catheterbased) have been reported. ${ }^{10-14}$ In our study, $30 \%$ of patients required reintervention; $58 \%$ had not required 
reintervention at 10 years. When analyzing the rate of late events in published results, one should consider that the presented series reports the largest number of patients with the longest follow-up. There was no specific time course for reintervention risk, with a continual risk for reintervention making close lifetime follow-up advisable. Despite a significant reintervention rate, no late mortality occurred upon reintervention. Furthermore, the functional outcomes were encouraging, with the majority of patients having normal biventricular function.

Regarding causes for reintervention, the literature ${ }^{9,10,12}$ reports more frequent right-sided lesions (RVOT and PA). Our experience, similar to that of Soszyn and colleagues, ${ }^{11}$ differed, with more procedures on the left side (LVOT, aortic valve, and arch). The $37 \%$ incidence of associated aortic arch obstruction seen in our patients, the lowest observed in reported series (rates of $50 \%$ to $80 \%$ ), ${ }^{10-14}$ may explain this discrepancy, with a consequently lower rate of RVOTO recurrence. Supporting this analysis is the finding that a native PA/aorta ratio $>2$ (associated with arch obstruction), ie, a smaller neopulmonary orifice, resulted in a higher reintervention rate for RVOTO.

\section{Risk Factors for Reintervention}

In the literature, several preoperative anatomic indicators have been identified as risk factors for reinterventions, such as aortic arch obstruction, preoperative subaortic RVOTO, side-by-side arteries, and PA to aorta mismatch. ${ }^{12,21}$ In our experience, similar to that of Comas and colleagues, ${ }^{22}$ the reintervention rate was higher in patients with arch obstruction.

In these patients, arch obstruction resulted in a larger native pulmonary root (a higher native PA-to-aorta diameter ratio), and a higher rate of postoperative grade- 2 AR. These dilated neoaortic roots, further enlarged by coronary buttons, showed a higher risk for late regurgitation. We previously reported that the postoperative neoaortic valve regurgitation was related to great artery size discrepancy, and to the use of valsalva sinus stitches when closing the VSD through the PA. ${ }^{23,24}$ The routine use of patch augmentation for arch repair, and the avoidance of valsalva stitches, may reduce neoaortic valve dysfunction. In addition, AR by neoaortic root dilatation after the ASO might develop over time. Previous banding (distorting neoaortic root and increasing flow velocity across the valve), 2-stage repair, and older age were identified as risk factors for AR and root dilatation. ${ }^{11,25}$ With the modern-day single-stage management of TBA, as in our cohort, these factors no longer have an impact, thus unveiling the role of aortic arch obstruction. In these patients, reduction of neoaortic root at the time of the ASO may be required to prevent further dilatation or AR.

Furthermore, as mentioned, aortic arch obstruction was associated with hypoplasia of the native RVOT and a subsequent higher rate of reintervention for RVOTO.
Meticulous echocardiographic assessment of the RVOT, its routine intraoperative inspection, and the division of any obstructive muscular bands was adopted to prevent this complication.

Lastly, in the early course of our experience, direct arch repair without patch augmentation was used in 5 patients, also resulting in significant recurrence of coarctation. Patch augmentation was then systematically used. The strategy for recoarctation management was a function of the initial repair procedure: homograft patch shrinkages were primarily managed by transcatheter procedures, whereas recoarctation after direct anastomosis was primarily managed by surgical patch augmentation.

\section{CONCLUSIONS}

In the largest reported series to date, it is shown that correction of TBA with an ASO can be achieved with low mortality rates and good long-term outcomes. Mortality is confined to the first postoperative year and is mainly associated with unfavorable coronary artery patterns. Despite the continual rate of reinterventions, survival beyond the first year remains steady over more than 10 years of follow-up, with sustained functional outcome. Initial aortic arch obstruction represents the main factor influencing late outcome: it significantly correlates with the intracardiac and extra-cardiac anatomy of the malformation, resulting in unbalanced outflow tracts and great vessels, thereby influencing rate and type of reintervention.

Further improvement of outcomes after application of this strategy may require that 3 issues be addressed:

1. identification of lesions at risk for early postoperative myocardial ischemia in patients with complex coronary pattern;

2. prevention of adverse events on the neoaortic root of patients with initial aortic obstruction (routine aortic arch patch augmentation and modified technique for transpulmonary closure of the VSD);

3. identification and preventive management of RVOT structures at risk for further obstruction (systematic infundibular resection).

You can watch a Webcast of this AATS meeting presentation by going to: http://webcast.aats.org/2014/files/Tuesday/ 20140429_320PM_340PM_Mathieu_Vergnat.mp4

The authors thank Dr A.S. Jannot for statistical coding expert support.

\section{References}

1. Walters HL III, Mavroudis C, Tchervenkov CI, Jacobs JP, Lacour-Gayet F, Jacobs ML. Congenital heart surgery nomenclature and database project: double outlet right ventricle. Ann Thorac Surg. 2000;69:S249-63.

2. Taussig HB, Bing RJ. Complete transposition of the aorta and a levoposition of the pulmonary artery; clinical, physiological, and pathological findings. Am Heart J. 1949;37:551-9. 
3. Konstantinov IE. Taussig-Bing anomaly: from original description to the current era. Tex Heart Inst J. 2009;36:580-5.

4. Stellin G, Zuberbuhler JR, Anderson RH, Siewers RD. The surgical anatomy of the Taussig-Bing malformation. J Thorac Cardiovasc Surg. 1987; 93:560-9.

5. Yacoub MH, Radley-Smith R. Anatomic correction of the Taussig-Bing anomaly. J Thorac Cardiovasc Surg. 1984;88:380-8.

6. Serraf A, Lacour-Gayet F, Bruniaux J, Losay J, Petit J, Touchot-Kone A, et al. Anatomic repair of Taussig-Bing hearts. Circulation. 1991;84:III200-5.

7. Kawashima Y, Fujita T, Miyamoto T, Manabe H. Intraventricular re-routing of blood for the correction of Taussig-Bing malformation. J Thorac Cardiovasc Surg. 1971;62:825-9.

8. Kawashima Y, Matsuda H, Yagihara Y, Shimazaki Y, Yamamoto F, Nishigaki K, et al. Intraventricular repair for Taussig-Bing anomaly. J Thorac Cardiovasc Surg. 1993;105:591-6.

9. Wetter J, Sinzobahamvya N, Blaschczok HC, Cho MY, Brecher AM, Gravinghoff LM, et al. Results of arterial switch operation for primary total correction of the Taussig-Bing anomaly. Ann Thorac Surg. 2004;77:41-6.

10. Alsoufi B, Cai S, Williams WG, Coles JG, Caldarone CA, Redington AM, et al. Improved results with single-stage total correction of Taussig-Bing anomaly. Eur J Cardiothorac Surg. 2008;33:244-50.

11. Soszyn N, Fricke TA, Wheaton GR, Ramsay JM, d'Udekem Y, Brizard CP, et al. Outcomes of the arterial switch operation in patients with Taussig-Bing anomaly. Ann Thorac Surg. 2011;92:673-9.

12. Griselli M, McGuirk SP, Ko CS, Clarke AJ, Barron DJ, Brawn WJ. Arterial switch operation in patients with Taussig-Bing anomaly-influence of staged repair and coronary anatomy on outcome. Eur J Cardiothorac Surg. 2007;31: 229-35.

13. Schwarz F, Blaschczok HC, Sinzobahamvya N, Sata S, Korn F, Weber A, et al. The Taussig-Bing anomaly: long-term results. Eur J Cardiothorac Surg. 2013; 44:821-7.

14. Hayes DA, Jones S, Quaegebeur JM, Richmond ME, Andrews HF, Glickstein JS, et al. Primary arterial switch operation as a strategy for total correction of Taussig-Bing anomaly: a 21-year experience. Circulation. 2013;128:S194-8.

15. Bradley TJ, Karamlou T, Kulik A, Mitrovic B, Vigneswaran T, Jaffer S, et al. Determinants of repair type, reintervention, and mortality in 393 children with double-outlet right ventricle. J Thorac Cardiovasc Surg. 2007;134: 967-73.

16. Van Praagh R. What is the Taussig-Bing malformation? Circulation. 1968;38: 445-9.

17. Yacoub MH, Radley-Smith R. Anatomy of the coronary arteries in transposition of the great arteries and methods for their transfer in anatomical correction. Thorax. 1978;33:418-24.

18. Sarris GE, Chatzis AC, Giannopoulos NM, Kirvassilis G, Berggren H, Hazekamp M, et al. The arterial switch operation in Europe for transposition of the great arteries: a multi-institutional study from the European Congenital Heart Surgeons Association. J Thorac Cardiovasc Surg. 2006;132:633-9.

19. Legendre A, Losay J, Touchot-Koné A, Serraf A, Belli E, Piot JD, et al. Coronary events after arterial switch operation for transposition of the great arteries. Circulation. 2003; 108:II186-90.

20. Legendre A, Chantepie A, Belli E, Vouhé PR, Neville P, Dulac Y, et al. Outcome of coronary artery bypass grafting performed in young children. $J$ Thorac Cardiovasc Surg. 2010;139:349-53.

21. Sinzobahamvya N, Blaschczok HC, Asfour B, Arenz C, Jussli MJ, Schindler E, et al. Right ventricular outflow tract obstruction after arterial switch operation for the Taussig-Bing heart. Eur J Cardiothorac Surg. 2007;31:873-8.

22. Comas JV, Mignosa C, Cochrane AD, Wilkinson JL, Karl TR. Taussig-Bing anomaly and arterial switch: aortic arch obstruction does not influence outcome. Eur J Cardiothorac Surg. 1996;10:1114-9.

23. Mohammadi S, Serraf A, Belli E, Aupecle B, Capderou A, Lacour-Gayet F, et al. Left-sided lesions after anatomic repair of transposition of the great arteries, ventricular septal defect, and coarctation: surgical factors. J Thorac Cardiovasc Surg. 2004; 128:44-52.

24. Losay J, Touchot A, Capderou A, Piot JD, Belli E, Planché C, et al. Aortic valve regurgitation after arterial switch operation for transposition of the great arteries: incidence, risk factors, and outcome. J Am Coll Cardiol. 2006;47: 2057-62.

25. Schwartz ML, Gauvreau K, del Nido P, Mayer JE, Colan SD. Long-term predictors of aortic root dilation and aortic regurgitation after arterial switch operation. Circulation. 2004;110:II128-32.

\section{Discussion}

Dr Christian Pizarro (Wilmington, Del). I would like to congratulate Dr Vergnat and colleagues for a great presentation on 1 of the largest series of surgery for Taussig-Bing anomaly in the contemporary era.

As we know, Taussig-Bing anomaly represents a considerable surgical challenge, owing to a combination of anatomic features, including right ventricular outflow obstruction, arch obstruction, and abnormal coronary patterns. These anatomic features frequently contribute to higher mortality and reintervention rates compared with simpler forms of transposition.

Performing a retrospective review of their experience over 13 years, the authors have attempted to elucidate risk factors associated with poor outcome, to inform the decision about the most suitable surgical strategy.

Arch obstruction is not infrequent in this patient population, and surgical management of this issue at the time of arterial switch not only adds to the complexity of the repair, but also can lead to morbidity and the need for reintervention. In this cohort, the incidence of arch obstruction was notably lower compared with that in previous reports, which cite $52 \%$ to $80 \%$. What do you attribute this to? Is this a product of regional referral practices, or is it possible that some of these patients did not reach care in time?

Dr Vergnat. Indeed, there was a difference between our cohort and other literature cohorts, but I do not have any explanation for that.

Dr Pizarro. Very well. As we all know, these operations are challenging, and the technical details are very important. Coronary transfer can be quite complex. As you showed us, all early deaths occurred in the first 24 hours and were associated with coronary ischemia. Similarly, all late deaths were associated with coronary ischemia. Specific coronary artery anatomy was associated with poor outcome, as you alluded to-Yacoub class $\mathrm{C}$ and $\mathrm{E}$. In light of these findings, have you modified the patient selection for primary repair, or have you modified the transfer techniques in these cases?

Dr Vergnat. Currently, we have only the results of this retrospective study. So, in view of these, what will be the future course? At present time, we still systematically use this repair strategy. The first improvement is to try to identify lesions at risk for early ischemia and take a more aggressive approach when types $\mathrm{C}$ and $\mathrm{E}$ are encountered for these patients. But we do not want to change the initial strategy of arterial switch. The goal is to eliminate this postdischarge first-year mortality by identifying such lesions with a more aggressive postoperative imaging strategy, possibly with coronary CT, or even angiography. But we still use this kind of repair for these patients, regardless of coronary artery patterns.

Dr Pizarro. Multiple series have reported different risk factors for mortality, including the relationship and position of the great arteries, the presence of arch hypoplasia, and coronary artery anomalies, as well as additional ventricular septal defects. Based on your experience, are there any scenarios in which primary biventricular repair might not be the best management strategy, or is it just a matter of modifying the timing of the procedure? 
Dr Vergnat. We believe strongly that the primary repair is the key, and any delay in the repair is not good for these patients because it will further damage the neoaortic valve and negatively affect late results. So, as clearly demonstrated in the literature, primary repair should be performed for these patients to prevent any damage that might require further correction. Thus, we think primary repair is the key for these patients.

Dr Pizarro. Given the high incidence of abnormal coronary anatomy and the lasting effects on coronary transfer, with potential for ischemia in this patient population, can you tell us how you monitor these patients, and what criteria you use to assess the adequacy of coronary function before providing clearance for competitive sports activities?

Dr Vergnat. We did not perform supplementary coronary testing for these specific Taussig-Bing patients, but our approach for arterial switch patients is to perform a CT examination of the coronary arteries around 5 years of age, to identify any lesions and to be more aggressive if any lesions are found on the CT.

Dr Pizarro. I would like to congratulate you and your colleagues for another important contribution from MarieLannelongue on the management of this challenging group of patients.

Dr Christopher A. Caldarone (Toronto, Ontario, Canada). Could I follow up a little bit on that question of coronaries that Christian brought up? Christian's question about whether to clear the coronaries in time for them to play competitive sports-I thought what he was going to say is: How do you clear the coronaries in order to leave the operating room? Because the intraoperative diagnostic studies may actually be a critical issue here-to identify latent threats in terms of coronary artery supply while in the operating room, when there is still an opportunity to revise it. So how do you assess the adequacy of coronary perfusion in the operating room? And do you think that may actually have an influence on your ability to prevent or ameliorate the coronary issues in the early postoperative period?

Dr Vergnat. You have 2 kinds of coronary deaths in this series. You have the very early, in the first day there is an event and there is a coronary death; and you have the late patients, in the first postoperative year. Clearly, with the more aggressive identification of lesions in the weeks after surgery, we can address this mortality in the first year. That is the key for these patients.

For the very early patient, it is much more difficult. So, for example, 1 had coronary perfusion that was not good during surgery, so there was an attempt to reposition the right coronary artery, but subsequently, there was heart failure, and he suddenly died of ventricular fibrillation. So that was assessed peroperatively. If there is any obvious evidence that there is not good perfusion, then we definitely reposition the button. For the other case, the perfusion was good, but in the first postoperative day, the ventricular function declined, and there was sudden cardiac arrest that was resuscitated, but 2 hours later, there was a second arrest, and we were not able to put that patient inside the catheterization lab to get some information, but that should happen, if we have the time to do it.

Dr Emri Belli (Le Plessis Robinson, France). I would like to add a comment on this, because coronary events in Taussig-Bing surgery seem to be a given. From 2200 arterial switches, we observed an obviously higher rate of coronary anomaly, and a high rate of type $\mathrm{C}$ anatomy, which is associated with a higher rate of coronary events postoperatively. What has changed during this study period is that, during the early portion of the experience, there was no routine extracorporeal membrane oxygenation (ECMO) use in the OR or the ICU. The second comment is that patients at risk for postoperative myocardial ischemia are now systematically undergoing an angiogram before discharge. Post-discharge deaths are often related to lesions that can be managed with balloon dilation without any additional procedure, because in this phase, problems are often related to coronary wall inflammation.

Dr Vergnat. Just very quickly, one of the very first deaths was put on ECMO, and had an angiogram the week after, but never recovered. So if we have the time, we bring them into the catheterization lab.

Dr Pedro del Nido (Boston, Mass). One of the 3 known complications of the true Taussig-Bing anomaly is coronary, as you pointed out - arch obstruction - and late subaortic obstruction is a known problem. The main reason for that is that, typically, in the classic Taussig-Bing, there is a true double outlet, and that is separation of the AV valve from the semilunar valve; in other words, a double conus. The definition of the $50 \%$ rule for double outlet was actually Bob Anderson's definition, not Van Praagh's. And if you think about it, the greater the separation is from the mitral valve to the semilunar valve, the bigger the opportunity you have for creating subaortic obstruction in these children, late, because that tunnel is made out of nongrowing synthetic material.

I was surprised to some degree to find that you have very little in the way of late subaortic obstruction. And I am wondering, because it is a definitional issue, how many of your patients had double outlet right ventricle- based purely on the fact that for $50 \%$, the semilunar valve was coming off the right ventricle and there was fibrous continuity between the mitral valve and the semilunar-and how many had true double outlet, with real separation?

Dr Vergnat. There was a $100 \%$ rate of mitral pulmonary discontinuity. That was a criterion we did not want to exclude.

Dr del Nido. Because that is not what you stated in your introduction. So that is important, to clarify that-

Dr Vergnat. Yes, of course.

Dr del Nido. - Doing that kind of tunnel, especially when you have that much separation between the mitral and the pulmonary, and you are trying to do this long baffle-there are many opportunities to create narrowing, particularly if you do these in young infants, and as you follow them as they grow.

Dr Belli. One more comment. We are very supportive of the definition from Van Praagh, instead of this 50\% rule. In fact, double outlet right ventricle is when $100 \%$ of both arteries arise from the right ventricle. And on the database, we went back 1 by 1 (Mathieu did the hard work), for every patient even classified as TGA/VSD, and found a couple Taussig-Bing, and deleted several "false" Taussig-Bing as defined in the operating report, probably because of malalignment-type VSD. The selection criteria included that in preoperative or intraoperative examination, bilateral infundibulum was present.

Dr Victor Tsang (London, United Kingdom). Pedro mentioned 3 points. I would like to add a fourth point. For the last point in the 
conclusion slide, the preventive management of the RVOT, we routinely do a prophylactic resection.

But I would like to ask 1 question. Under what circumstances in your patient cohort could you not do a Lecompte?
Dr Vergnat. We did a Lecompte in $100 \%$ of the patients. That may explain why we had more problems with pulmonary arteries. There were some late reinterventions on the pulmonary arteries, but fewer than on the pulmonary outflow tract.

\title{
EDITORIAL COMMENTARY
}

\section{The Taussig-Bing anomaly turns 65: What we have learned in a lifetime}

\author{
Frank A. Pigula, MD
}

See related article on pages 1124-32.

The article in this issue of the Journal by Vergnat and colleagues reports the largest single-institution experience with the surgical treatment of double-outlet right ventricle (DORV) with subpulmonary ventricular septal defect (VSD), also known as the Taussig-Bing anomaly. This report contributes significantly to the aggregate surgical experience with this uncommon disease and continues to clarify a generally accepted management approach.

The outcomes reported here are excellent, and they do provide important information, namely the identification of high-risk coronary artery patterns (Yacoub classes C and $\mathrm{E})$. This recognition has prompted Vergnat and colleagues to pursue routine postoperative surveillance of high-risk patients, including routine angiography. Whether this preemptive approach will mitigate postrepair ischemic events is unclear; with mortality exceeding $20 \%$ for patients with high-risk coronary patterns, however, the effort seems justified.

Likewise, other findings reported here are largely consistent with previous reports; there is a relationship between a smaller aorta and reoperation for subsequent right ventricular outflow tract obstruction. Although there is low risk of

From the Department of Cardiothoracic Surgery, Children's Hospital of Boston, Boston, Mass.

Disclosures: Author has nothing to disclose with regard to commercial support.

Received for publication Nov 3, 2014; accepted for publication Nov 4, 2014; available ahead of print Dec 4, 2014.

Address for reprints: Frank A. Pigula, MD, Pediatric Cardiothoracic Surgery, Department of Cardiothoracic Surgery, Children's Hospital of Boston, 300 Longwood Ave, Farley 144, Boston, MA 02115 (E-mail: Frank.Pigula@tch.Harvard.edu).

J Thorac Cardiovasc Surg 2015;149:1132-3

$0022-5223 / \$ 36.00$

Copyright (c) 2015 by The American Association for Thoracic Surgery

http://dx.doi.org/10.1016/j.jtcvs.2014.11.010 mortality after the first year, there continues to be need for subsequent reinterventions (Figure 1, $C$, in the article of Vergnat and colleagues)..$^{1-3}$

This report, however, also describes findings that are at odds with previous experience. For instance, the need for reintervention on the left ventricular outflow tract and aorta exceeds the incidence of reintervention on the right ventricular outflow tract and pulmonary arteries combined (Figure $1, D$, in the article of Vergnat and colleagues). One explanation may be technical. Vergnat and colleagues' preferred institutional approach to VSD closure was through the native pulmonary valve $(83 \%)$, but they have also previously reported that postoperative neo-aortic valve regurgitation is related to the placement of VSD sutures within the sinuses of Valsalva. In fact, there were 5 neoaortic valve replacements and 3 neo-aortic valve repairs among these 69 patients. As an alternative, it has been my experience that a right ventriculotomy provides excellent access to the VSD, allows muscular resection and patching of the right ventricular outflow tract, and is well tolerated. With this approach, the incidence of surgical neo-aortic valve intervention among these patients has been extremely low.

Other possible explanations for differences between this study and others become apparent when one carefully considers the evolution of our clinical understanding of the Taussig-Bing malformation. It was in 1949 that Taussig and Bing first described an unusual form of DORV. This index specimen, which was to become known as the TaussigBing malformation, was reexamined in 1968 by Richard Van Praagh. ${ }^{4}$ Van Praagh ${ }^{4}$ summarized the qualifying anatomy of the specimen as "double-outlet right ventricle with semilunar valves side-by-side and approximately at the same height, a bilateral conus, and a subpulmonary ventricular septal defect."

The index specimen now serves as an anatomic construct upon which we can hang our conceptual understanding of 